\title{
Território e Sociedade na Era da Globalização: Apontamentos teóricos sobre os Novos Muros na Europa
}

\author{
Sara Aparecida de Paula ${ }^{1}$ \\ Leonardo Freire de Mello ${ }^{2}$
}

\begin{abstract}
RESUMO
O conceito clássico de território conecta-se com a identidade, o espaço geográfico e o poder do Estado-Nação delimitado através do estabelecimento e manutenção de fronteiras. No entanto, este conceito vem passando, desde a segunda metade do século XX, por sistemáticas transformações, influenciadas, sobretudo, pela era da globalização com a consolidação de processos de desterritorialização em que os fluxos de pessoas, capitais e informações são cada vez mais fluidos, provocando mudanças bruscas no ambiente, na sociedade e nas suas dinâmicas. Sendo o território o meio onde os fenômenos sociais efetivamente ocorrem, é imprescindível ter uma visão integradora sobre a teoria e a realidade, considerando a sociedade, o ser humano e o ambiente uma unidade interativa. Assim, este trabalho propõe uma análise teórica sobre o conceito de território bem como suas transformações sob o viés das dinâmicas dos novos muros na Europa.
\end{abstract}

Palavras-Chave: Território, Sociedade, Globalização, Teoria.

\begin{abstract}
The classical definition of territory connects with the identity, the geographical space and the power of the nation-state delimited through the establishment and maintenance of borders. However, since the second half of the twentieth century, this concept has been changed by systematic transformations, mainly influenced by the era of globalization and the consolidation of deterritorialization processes in which people, capital and information flows are becoming increasingly fluid, causing sudden changes in the environment, in society and in its dynamics. Since territory is the substract in which social phenomena effectively occur, it is essential to have an integrative view on theory and reality, considering society, human beings and the environment as an interactive unit. Thus, this paper proposes a theoretical analysis on the concept of territory as well as its transformations under the bias of the dynamics of the new walls in Europe.
\end{abstract}

Keywords: Territory, Society, Globalization, Theory.

\footnotetext{
${ }^{1}$ Graduada no Bacharelado em Ciências e Humanidades e discente do Bacharelado em Relações Internacionais da Universidade Federal do ABC. Observatório das Migrações e da Mobilidade Espacial do ABC - MobiABC; Grupo de Estudos Paradoxo: Antropoceno e Felicidade. sara12app@gmail.com

${ }^{2}$ Observatório das Migrações e da Mobilidade Espacial do ABC - MobiABC; Grupo de Estudos Paradoxo: Antropoceno e Felicidade. Programa de Pós-Graduação em Planejamento e Gestão do Território e Bacharelado em Planejamento Territorial - Universidade Federal do ABC. leonardo.mello@ufabc.edu.br
} 


\section{Introdução}

O conceito de território, em toda sua polissemia, se conecta a uma variedade de concepções e perspectivas de pensamento.

Jean Gottmann, ao fazer um estudo da cronologia do conceito, relata que "território" confunde-se, muitas vezes, com "espaço". Por isso, para ele, define-se território como "uma porção do espaço geográfico que coincide com a extensão espacial da jurisdição de um governo. Ele é o recipiente físico e o suporte do corpo político organizado sob uma estrutura de governo" (GOTTMANN, 2012, p.523).

Claude Raffestin, por sua vez, explica que o território se forma a partir do espaço, sendo resultado de processos sociais como a interação entre infraestrutura, forças de trabalho e relações de produção. Ainda segundo o autor, os indivíduos e/ou os grupos ocupam o espaço de maneira aleatória ou regular, respondendo a fatores físicos, geográficos, de acessibilidade, psicológicos e econômicos (RAFFESTIN, 1980, pp. 143-150).

Rogério Haesbaert (2007) destaca o território como um elemento de dupla personalidade, afirmando que este relaciona-se com o poder como forma de dominação político-jurídica e agrega, ainda, um caráter mais simbólico de sentimento de posse e pertencimento, ou seja, um lado mais cultural. Desta forma, o elemento material e o subjetivo conectam-se amplamente em um processo contínuo de construção social do espaço, em que o território possui um caráter híbrido e mutável.

De acordo com essa abordagem, entende-se o território como instrumento de coesão do Estado Moderno, que tem início com a Paz de Vestfália de 1648. Neste acordo, que pôs fim à Guerra dos 30 Anos, houve a articulação de Estados Nacionais em um sistema de delimitação de espaços geográficos, ou seja, a demarcação de fronteiras. As fronteiras, como uma faceta da "human territoriality" de Robert Sack (1983), demonstram sua característica de personificação do poder do Estado e caracterização da nacionalidade de um determinado conjunto de pessoas pertencentes àquele espaço. Por isso o território agrega uma ideia de identidade e de conexão do povo, assim como ideais de proteção.

Do ponto de vista da geografia política clássica, Ratzel (1983) coloca que o Estado não seria concebível sem o território e sem fronteiras. Para ele, o território representa a conexão ou a relação de uma sociedade com o solo. Do ponto de vista físico, o território relaciona-se ao seu papel de fonte de recursos para a manutenção da vida.

Essa necessidade resulta numa série de avanços tecnológicos e fenômenos sociais como o domínio da agricultura e o estabelecimento de comunidades em contraposição ao nomadismo, interferindo, por exemplo, nas novas relações produtivas e no progresso técnico 
da humanidade. Já o caráter simbólico do território, no qual os indivíduos têm o sentimento de pertencimento é parte essencial para a coesão do espaço.

Outro elemento importante na análise de Ratzel, é a ideia de que cada território possui nuances diversas em consideração a sua natureza, seu contexto e, por isso, há dois tipos de Estados e seus territórios.

Em um deles, vive-se exclusivamente do solo que se habita, isto é, a produção é suficiente para a manutenção do povo e, consequentemente do Estado. Por outro lado, há aqueles que são obrigados a recorrer aos recursos de outras terras em busca de condições para sua sobrevivência como a garantia do acesso à alimentação. É nesta ideia que se estabelece a importância do comércio e das trocas econômicas, acentuadas na contemporaneidade (RATZEL, 1983).

Essa questão das trocas pode ser conjugada com a análise de Leila Christina Dias (2000) sobre as redes e seu papel, tanto na organização do território, como na modificação dos espaços. Em seu trabalho ela relata a transformação das redes vis à vis às inovações decorrentes do século XVIII/ XIX e acentuadas durante o século XX.

Em outras palavras, é interessante contextualizar os séculos XVIII e XIX como o nascimento da Revolução Industrial e de modificação nas relações entre os Estados e consequentemente entre os territórios (HOBSBAWN, 1999).

Esse processo é ainda mais difundido durante o século $\mathrm{XX}$, onde inovações nos sistemas de transportes e comunicações "redesenharam o mapa do mundo" (DIAS, 2000, p. 143).

\section{Discussão}

É importante destacar que o planeta tem passado por um amplo processo de transformações. Para Anthony Giddens (1999) as mudanças iniciaram-se com o pensamento iluminista da Revolução Francesa e a Revolução Industrial em meados do século XVIII, revelando a centralidade da racionalidade humana, dos novos processos de produção e comércio, bem como a perspectiva de estabilidade produzida pelas inovações na ciência e na tecnologia.

Entretanto, essas transformações atingiram, nas últimas décadas, um nível nunca antes visto, configurando o que ficou conhecido como a Globalização. Para autores como Giddens e Bauman (2001), a globalização tem a capacidade de perpetrar diferentes esferas da vida 
humana, alterando aspectos como a economia, política, cultura e o ambiente em que se vive, e os conectando amplamente entre si.

Partindo deste ponto, Castells (1999) promove um debate sobre a globalização como processo de formação de sociedades em redes ou de nós interconectados, no qual, conclui a capacidade de perpetração das redes informacionais em toda a estrutura social, modificando as sociedades, os meios produtivos e o modo que eles se relacionam com o território.

Castells descreve a globalização como um processo que "transcende fronteiras [...] a sua lógica chega a países de todo o planeta e difunde-se através do poder integrado nas redes globais de capital, bens, serviços, comunicação, informação, ciência e tecnologia" (CASTELLS, 1999, p.18).

Emerge, ainda, a ideia do enfraquecimento do Estado como ator principal dos processos e dinâmicas territoriais, resultante da diluição das fronteiras e do surgimento e consolidação de uma identidade mais cosmopolita, fortemente baseadas em uma interdependência econômica. A transformação do capitalismo em meados da década de 1970 e ampliado com os pensamentos neoliberais das décadas de 1980 e 1990, permitiu que as distâncias se tornassem cada vez mais fluidas, relativas e pouco nítidas.

Essa diminuição de distâncias ou contração do espaço-tempo detectada por David Harvey também é debatida por Bauman (2001). Para o autor, a globalização permitiu o acesso rápido às informações e às troca de ideias e opiniões, bem como estimulou um significativo aumento nos fluxos de pessoas, mercadorias e serviços.

Neste cenário globalizado, Haesbaert $(2007,2011)$ relata um potencial semblante de desterritorialização, uma perda da ideia de território como este era conhecido até então, ou seja, como algo delimitado por fronteiras e controlado por Estados Nacionais.

Haesbaert explica que há duas vertentes sobre o entendimento de desterritorialização: na primeira, discute-se a fragilidade das fronteiras, ou seja, uma questão mais física, material e concreta; a segunda se refere a aspectos mais intangíveis e fortemente conectados a processos de hibridização cultural que dificultam a percepção e o entendimento das identidades contemporâneas (HAESBAERT, 2007, p.27).

É possível perceber novamente, a dupla característica do território como elemento político (manifestação do poder e gestão do espaço) e cultural (níveis psicológicos de pertencimento). Todavia, já que o território é fonte de recursos e espaço de circulação, é interessante e importante destacar o pano de fundo vinculado à vertente econômica. 
Tendo em vista esse debate sobre o fim dos territórios, Haesbaert o destaca como algo aparente e paradoxal, já que as políticas territoriais de segurança têm se ampliado por todo o globo. Exemplo disso, é o crescente número de muros sendo construídos nas fronteiras por todo o mundo como, por exemplo, o muro entre os Estados Unidos e o México, entre as Coréias, entre a Hungria e a Sérvia, entre a Palestina e Israel, entre outros. Haesbaert destaca que,

ao lado da fluidez globalizada das redes e da 'desterritorialização' (e/ou da multiterritorialidade) aparecem também os fechamentos, as tentativas de controle dos fluxos, da circulação, sobretudo da circulação de pessoas, da força de trabalho, dos migrantes [...] Nesse sentido, uma das estratégias aparentemente mais anacrônicas, hoje em dia, é a construção de novos muros [...] muitos foram os contextos em que fronteiras políticas adquiriram essa forma de materialização. Suas funções, é claro, mudaram muito ao longo do tempo [...] A difusão de fronteiras muradas surge em grande parte, também, em nome do mesmo discurso global da 'segurança', através de um Estado que claramente busca reconfigurar seu papel num mundo que já há algumas décadas busca decretar o seu debilitamento (HAESBAERT, 2011, p.10).

Ao definir os muros como um fenômeno social, é necessário colocá-los em duas vertentes, isto é, (1) o muro é algo físico, concreto, mas que, também, (2) pode ser invisível e traz consigo inúmeras questões simbólicas baseadas na segregação e no direito de pertencer ou não a determinado território.

Exemplo extremamente contemporâneo dessa discussão, é a chamada "camarotização" de espaços no Brasil, assim como a lógica do condomínio presente nas tentativas de configuração de um espaço intransponível para determinados grupos (DUNKER, 2015).

Através desta rápida congruência de ideias percebe-se um profundo contexto de mudanças em relação ao território, em seu cenário e na realidade em que se vive.

Neste sentido, Bauman (2016) notou que os fluxos da atualidade acentuam a discussão sobre pertencimento e identidade, em outras palavras, sobre o complexo e contraditório "Nós e os Outros" e a ampliação das desigualdades territoriais em diferentes lugares e diferentes proporções, provocando consequências como a dificuldade de acesso a espaços e seus recursos naturais, bem como, às consequências de tais ações.

Percebe-se que o advento da globalização propagou as ideias do neoliberalismo e de um mundo sem fronteiras, pelo menos dentro da perspectiva da economia e do sistema financeiro, fazendo com que os impactos locais podem ser sentidos em escala global e abrangente e vice versa. Sendo assim, há um novo entendimento sobre a escala conceitual dos fenômenos sociais e territoriais.

Stiglitz (2010) diz que o processo de globalização, em teoria, traria inúmeros benefícios, entretanto, o modo como foi manejado fez com que o poder de decisão se 
concentrasse nas grandes corporações. Além disso, também provocou altos níveis de desigualdade econômica e social em todo o mundo.

Os impactos dessa desigualdade também são relatadas por Ermínia Maricato. Para a autora, o neoliberalismo instigou a fragmentação territorial e a acentuação de segregação espacial. Em seus estudos sobre planejamento urbano na periferia do sistema capitalista, ela aponta que os impactos do neoliberalismo nas cidades são sentidos de forma bastante intensa no desemprego e no abandono de políticas sociais, o que, em particular nos casos das periferias, prejudica ainda mais um sistema já bastante fragilizado (MARICATO, 2011).

Sobre isso, a autora afirma que

o impacto da globalização nas cidades de todo o mundo - em decorrência da 'nova pobreza' e, por que não, da nova riqueza - foi responsável por algumas mudanças no caráter da segregação com a ocorrência das gated communities, guetos, cidadelas, condomínios fechados (MARICATO, 2011, p.9).

Ainda sob o viés da segregação em diferentes escalas, como já mencionado, é importante notar o mito da desterritorialização de Haesbaert. Para ele, a globalização carrega a ideia de perda ou desaparecimento de territórios, no entanto, essa questão seria um mito já que há, na verdade, processos complexos de (re)territorialização (HAESBAERT, 2007).

Desta forma, o autor propõe discutir a complexidade da contemporaneidade através do conceito de multiterritorialidade, pois ao contrário do território "unifuncional" da lógica capitalista hegemônica, o território é cada vez mais fluido, diverso e complexo.

Em seus textos, ele também relata as novas segregações espaciais através da securitização das fronteiras com a construção de muros e barreiras de contenção como cercas, o que corroboraria o "mito da desterritorialização".

Para o autor, apesar da globalização trazer um discurso de livre fluxo e fim das fronteiras (em diversos âmbitos), o que se vê é um mundo cada vez mais segregado, sendo esta segregação personificada, por exemplo, através da construção dos muros.

Esse aspecto é o que Robert Sack (1983) coloca como controle de acessibilidade na dinâmica "território-territorialidade". Além disso, o autor também relaciona esse "controle" com regras simbólicas de inclusão ou exclusão.

Fato é que essa estratégia de contenção geralmente está vinculada com o fluxo de determinados grupos como os migrantes e refugiados, pessoas fugindo de sistemas políticos destruídos ou de desastres naturais cada vez mais potencializados pelas mudanças ambientais decorrentes, sobretudo, da própria ação humana.

De acordo com relatório da Organização das Nações Unidas - ONU (2016), o número de conflitos no mundo tem crescido sistematicamente, principalmente na África e no Oriente 
Médio. Cabe destacar que estes conflitos têm diferentes nuances, ou seja, ao mesmo tempo em que desestruturam a política e economia de um país e o acesso aos recursos, fortalecem, também, cada vez mais o fluxo de migrantes e refugiados em busca de sobrevivência e condições dignas de vida.

Exemplo gritante disso é o que tem acontecido na Europa. De acordo com o Alto Comissariado das Nações Unidas para os Refugiados - ACNUR (2015), no ápice da crise dos refugiados provenientes principalmente da Síria (país que está em Guerra Civil desde 2011), praticamente um milhão de pessoas haviam fugido para a Europa. Este fato incentivou alguns governos europeus a promoverem políticas de contenção como, por exemplo, a construção os muros já mencionados.

O caso da Europa torna-se ainda mais complexo ao se considerar o seu próprio processo de integração interna. Para Sebastian Rosato (2011) a base da União Européia - UE parte do trinômio integração econômica, securitária e cultural. Para ele, a UE foi, até a primeira década do século XXI, um caso de sucesso no tema do regionalismo. No entanto, a crise econômica de 2008 demonstrou as fraquezas do sistema, que apostou no âmbito econômico e deixou de lado os outros dois elementos do trinômio supracitado.

Fato é que a integração europeia funcionou como uma resposta à globalização. No entanto, atualmente enfrenta questionamentos e discussões sobre temas como soberania nacional e supranacionalidade, principalmente em relação às fronteiras e ao recebimento dos refugiados.

Sobre as fronteiras, a maior parte dos países é signatária do Acordo de Schengen, promulgado através do Tratado de Amsterdã (1997) e reforçado com o Tratado de Lisboa (2006). O Acordo de Schengen abrange 26 países que assumem a responsabilidade de prover a segurança das fronteiras externas e garantir a abertura das fronteiras internas (EUROPEAN UNION, 2014).

Além disso, o documento da UE ainda diz que "a fronteira externa também precisa de se manter aberta às pessoas que vêm para trabalhar ou que procuram escapar da guerra ou de perseguições" (UNIÃO EUROPEIA, 2006).

Percebe-se, então, que a UE apresenta acordos com decisões mútuas, entretanto, ela própria recentemente divulgou que pretende implementar sanções a países como a Polônia, a República Tcheca e a Hungria, pelo não recebimento de refugiados e, em especial, no caso da Hungria, pela construção de cercas em suas fronteiras, infringindo o acordo de Schengen. O 
país também construiu campos de concentração onde os refugiados permanecem em condições degradantes (DEUTSCH WELLE, 2017).

Estes exemplos são parte do mito da desterritorialização explanado por Haesbaert, pois apesar do discurso de abertura, percebe-se uma tendência cada vez maior de fechamento das fronteiras e do cerceamento da livre circulação de pessoas.

O professor da University of Hawaii Reece Jones (2015) chamou 2015 de o "Year of Border Walls", em seu artigo para o Project Syndicate, assinalando o fato de que, até o fim da Segunda Guerra Mundial, haviam cinco muros pelo mundo e que, no período posterior, principalmente nas duas últimas décadas, esse número subiu para 65 .

Por fim, entende-se que os muros não são ferramentas tão úteis para conter o movimento principalmente em um mundo globalizado, servem apenas para agravar a situação degradante dos migrantes e refugiados que se arriscam em busca de sobrevivência. Além disso, impulsiona o comércio da vigilância e o grave problema do tráfico de pessoas. (ROMDHANI, 2016)

\section{Considerações Finais}

Através da discussão apresentada é possível perceber como o conceito de território vem cada vez mais se tornando algo flexível e mais amplamente relacionado com o seu contexto. Por muito tempo, o território esteve conectado com a ideia de poder do Estado através do estabelecimento e manutenção de fronteiras, bem como com uma percepção mais nítida sobre identidade e pertencimento.

O processo de globalização traz à tona toda uma série de questionamentos acerca desses elementos, pois infere que a identidade nacional passaria, naturalmente, a ser global, assim como os fluxos de pessoas, mercadorias, capital e ideias tornariam-se cada vez mais intensos, fáceis e profundos.

No entanto, apesar dos fluxos de capital e mercadorias terem, indiscutivelmente, sido facilitados e se intensificado em uma escala sem precedentes, o mesmo não ocorre com os fluxos de pessoas e este fato pode ser corroborado pela crescente construção de cercas, muros e outros métodos de contenção de pessoas nas fronteiras geográficas dos países.

Estas contradições entre o discurso popularizado pelos processos de globalização econômica e financeirização da economia global versus a realidade nua e crua dos inúmeros e crescentes campos de refugiados e outros aglomerados de exclusão - como definidos por Rogério Haesbaert - tanto nos países periféricos quanto nas periferias dos estados centrais, acentuam as críticas ao sistema econômico e político hegemônico, além de apontar para a 
iminência da ocorrência de conflitos em escalas espaciais e de intensidade sem precedentes desde o final da Segunda Guerra Mundial.

As perguntas que se precisa responder - cada vez com mais urgência - se relacionam com o quanto os atuais sistemas democráticos serão capazes de lidar com tais problemas e produzir soluções que não tragam, em seu bojo, ameaças à própria manutenção da Democracia, abrindo caminho para a ascensão de regimes autoritários e fascistas, cercados por muros e fortemente militarizados, em permanente conflito interno e externo pelo acesso a recursos naturais cada vez mais escassos e ameaçados pela própria lógica do sistema econômico global e suas consequências sociais, políticas e ambientais. 


\section{Referências Bibliográficas}

ACNUR. Um milhão de refugiados e migrantes fugiram para a Europa em 2015. 2015. Disponível em: $<$ http://www.acnur.org/portugues/noticias/noticia/um-milhao-de-refugiados-emigrantes-fugiram-para-a-europa-em-2015/ > . Acesso em: 20 de Setembro de 2017.

BAUMAN, Z. Modernidade líquida. Rio de Janeiro: Jorge Zahar Ed., 2001.

Estranhos à nossa porta. Rio de Janeiro: Jorge Zahar Ed., 2016.

CASTElLS, M. A Sociedade em Rede. São Paulo: Paz e Terra, 1999, p. 18.

DEUTSCHE WELLE. UE entra com ações contra Hungria, Polônia e República Tcheca. Dezembro de 2017. Disponível em: < http://www.dw.com/pt-br/ue-entra-coma\%C3\%A7\%C3\%B5es-contra-hungria-pol\%C3\%B4nia-e-rep\%C3\%BAblica-tcheca/a$41699410>$. Acesso em 07 de Dezembro de 2017.

DIAS, L. C. Redes: emergência e organização. In: Iná E. de Castro; Paulo Cesar da C. Gomes; Roberto L. Corrêa. (Org.). Geografia: conceitos e temas. $2^{\text {a }}$ ed. Rio de Janeiro: Bertrand Brasil, 2000, v. 1, p. 141-162.

DUNKER, C. I. A Lógica do Condomínio. In: DUNKER, C. Mal estar, sofrimento e sintoma. São Paulo: Boitempo Editorial, 2015. p. 47-106.

GOTTMAnN, J. A Evolução do Conceito de Território. Boletim Campineiro de Geografia, [s.1.], v. 2, n. 3, p.523-545, fev. 2012.

HAESBAERT, R. Da multiterritorialidade aos novos muros: paradoxos da desterritorialização contemporânea. Niterói, Universidade Federal Fluminense, 2011. p.1-15. Disponível em <http://www.posgeo.uff.br/sites/default/files/da multiterritorialidade aos novos muros.pdf $>$. Acesso em 16 de Agosto de 2017.

O mito da desterritorialização: do "fim dos territórios" à multiterritorialidade. Rio de Janeiro: Bertrand Brasil, 2004. Capítulo 2 p. 35-98.

- Território e Multiterritorialidade: um debate. Geographia, Rio de

Janeiro, v. 9, n. 17, p.19-46, jul. 2007. Disponível em: <http://www.geographia.uff.br/index.php/geographia/article/viewFile/213/205>. Acesso em: 15 ago. 2017.

HOBSBAWM, E. J. A Era das Revoluções. 9.ed. São Paulo: Paz e Terra, 1999.

MARC, Alexandre. CONFLICT AND VIOLENCE IN THE 21ST CENTURY CURRENT TRENDS AS OBSERVED IN EMPIRICAL RESEARCH AND STATISTICS. United Nations. 2016. Disponível em: < https://www.un.org/pga/70/wpcontent/uploads/sites/10/2016/01/Conflict-and-violence-in-the-21st-century-Current-trendsas-observed-in-empirical-research-and-statistics-Mr.-Alexandre-Marc-Chief-SpecialistFragility-Conflict-and-Violence-World-Bank-Group.pdf> . Acesso em 20 de Setembro de 2017.

MARICATO, E. Globalization and Urban Policy. In: WORLD PLANNING SCHOOLS CONGRESS. Cidade do México, 2006.

RAFFESTIN, C. Por uma geografia do poder. São Paulo: Ática, 1980. 
RATZEL, Friedrich. O Solo, a Sociedade e o Estado. Revista do Departamento de Geografia, São Paulo, v. 2, n. 2, p.93-101, 1983.

ROMDHANI, Messaoud. Cercas altas não produzem bons vizinhos. Sur - Revista Internacional de Direitos Humanos. 2016. Disponível em: < http://sur.conectas.org/cercasaltas-nao-produzem-bons-vizinhos/> . Acesso em 10 de Setembro de 2017.

ROSATO, Sebastian. Europe's Troubles: Power Politics and the State of the European Project. International Security, Vol. 35, No. 4 (Spring 2011), pp. 45-68.

SACK, R. D. Human Territoriality: A Theory. Annals of the Association of American Geographers, Vol. 73, No. 1. (Mar., 1983), pp. 55-74. 